\title{
Article
}

\section{The Effect of 1-MCP on the Expression of Carotenoid, Chlorophyll Degradation, and Ethylene Response Factors in 'Qihong' Kiwifruit}

\author{
Yanfei Liu ${ }^{1,2,+}$, Guowen Lv ${ }^{1,+}$, Jiaxin Chai ${ }^{1}$, Yaqi Yang ${ }^{1}$, Fengwang Ma ${ }^{1}$ and Zhande Liu ${ }^{1, *}$ \\ 1 College of Horticulture, Northwest A\&F University, Xianyang 712100, China; lyfkiwi@nwafu.edu.cn (Y.L.); \\ lvgw@nwafu.edu.cn (G.L.); jxchai@nwafu.edu.cn (J.C.); yaqiyang98@nwafu.edu.cn (Y.Y.); \\ fwm64@nwsuaf.edu.cn (F.M.) \\ 2 College of Life Science, Northwest A\&F University, Xianyang 712100, China \\ * Correspondence: dezhanliu@nwafu.edu.cn \\ + Both authors contributed equally to this work.
}

Citation: Liu, Y.; Lv, G.; Chai, J.; Yang, Y.; Ma, F.; Liu, Z. The Effect of 1-MCP on the Expression of Carotenoid, Chlorophyll Degradation, and Ethylene Response Factors in 'Qihong' Kiwifruit. Foods 2021, 10, 3017. https://doi.org/10.3390/ foods10123017

Academic Editor: Stefania Masci

Received: 25 October 2021

Accepted: 2 December 2021

Published: 5 December 2021

Publisher's Note: MDPI stays neutral with regard to jurisdictional claims in published maps and institutional affiliations.

Copyright: (c) 2021 by the authors. Licensee MDPI, Basel, Switzerland. This article is an open access article distributed under the terms and conditions of the Creative Commons Attribution (CC BY) license (https:// creativecommons.org/licenses/by/ $4.0 /$ )

\begin{abstract}
The development of yellow color is an important aspect of fruit quality in yellow fleshed kiwifruit during fruit ripening, and it has a large influence on consumer preference. The yellow color is determined by carotenoid accumulation and chlorophyll degradation and is likely affected by ethylene production. This study investigates the expression of carotenoid, chlorophyll degradation, and ethylene response factors in 'Qihong' fruit, which had reached the near ripening stage (firmness $\approx 20 \mathrm{~N}$ ) and were either left untreated (controls) or treated with $0.5 \mu \mathrm{L} \mathrm{L}{ }^{-1}$ of $1-\mathrm{MCP}$ for $12 \mathrm{~h}$. Both the accumulation of $\beta$-carotene (not lutein) and degradation of chlorophyll $a$ and $b$ increased in response to the 1-MCP treatment, resulting in more yellow colored flesh in the 1-MCP treated fruit with higher carotenoid and lower chlorophyll contents. 1-MCP up-regulated AcLCY- $\beta$, $A c S G R 1$, and AcPAO2, but reduced the expression of AcCCD1. These four genes were correlated with the concentrations of $\beta$-carotene and the chlorophylls. The expression of three ethylene response factors, including Acc29730, Acc25620, and Acc23763 were delayed and down-regulated in 1-MCP treated fruit, showing the highest correlation with the expression of AcLCY- $\beta, A c S G R 1, A c P A O 2$, and $A c C C D 1$. Dual-Luciferase assays showed that 1-MCP treatment not only eliminated the inhibition of Acc23763 on the promoters of both AcPAO2 and AcLCY- $\beta$, but also reduced the activation of Acc29730 and Acc25620 on the AcCCD1 promoter. Our findings indicate that Acc29730, Acc25620, and Acc23763 may play an important role in the response to 1-MCP treatment during the fruit eating ripe stage, which likely altered the promoter activities of carotenoid and chlorophyll-related genes (AcPAO2, $A C L C Y-\beta$ and $A c C C D 1)$ to regulate their transcripts, resulting in more yellow color in the fruit flesh of 'Qihong'.
\end{abstract}

Keywords: kiwifruit; beta-carotene; chlorophyll degradation; 1-MCP; eating ripe stage

\section{Introduction}

Kiwifruit (Actinidia chinensis) is known as the 'king of fruit' because of its unique flavor and exceptional nutritional value (e.g., vitamin C), and has become one of the most recently developed and economically important fruit crops worldwide [1]. Yellow fleshed kiwifruit has become more widely preferred by consumers due to its brilliant color and rich carotenoids, compared with their green-fleshed cousins. Chlorophyll degradation and $\beta$-carotene accumulation are associated with changes in flesh color, and both kinds of pigments are responsible for the development of yellow color in kiwifruit during ripening [2-4].

Chlorophyll degradation is an important component of the de-greening process necessary for marketability of most yellow climacteric fruit during ripening (e.g., citrus, papaya, and banana) [5-8], and thus has become a special focus for an increasing number 
of researchers. It has been previously shown that ethylene is involved in chlorophyll degradation in fruit. For example, exogenous ethylene treatment accelerates chlorophyll degradation in mature green banana, citrus, and avocado fruit [9-11]. Treatment with the ethylene antagonist 1-methylcyclopropene (1-MCP) leads to retention of the green color in fruit by reducing chlorophyllase activity [6,12-14].

Ethylene also regulates carotenoid biosynthesis during fruit maturation. Hoeberichts et al. reported that ethylene treatment stimulates the $P S Y$ transcript level in tomato fruit [15]. Marty et al. suggested that applying ethylene to mature green apricots postharvest increases expression of the PSY and PDS genes, resulting in the accumulation of phytofluene and phytoene [16]. In durian fruit, ethylene affected the carotenoid accumulation by regulating the gene expression in the carotenoid pathway, including zeta-carotene desaturase (ZDS), lycopene beta-cyclase $(L C Y B)$, chromoplast specific lycopene beta-cyclase $(C Y C B)$ and beta-carotene hydroxylase $(B C H)$ [17]. 1-MCP treatment inhibits carotenoid biosynthesis in some fruit. However, this depends on the carotenoid compounds and whether the fruit can be induced by endogenous ethylene during ripening $[16,18,19]$. Carotenoid accumulation decreases in response to 1-MCP treatment of papaya fruit, compared to untreated control fruit [20]. 1-MCP applied before ripening also reduces carotenoid synthesis by inhibiting transcript levels of the PSY, ZDS, $L C Y B$, and $B C H$ genes in nectarines [21]. A slight inhibition of carotenoid accumulation and PSY expression were detected in 1-MCP-treated apricot [18].

Kiwifruit are classified as a climacteric fruit [22], and four distinct softening phases were clearly described during postharvest ripening [23]. Fruit at phase 1 and phase 2 did not produce endogenous ethylene but were highly sensitive to exogenous ethylene, and many fruit quality characters (e.g., color, flavor, and taste) were affected by the application of exogenous ethylene $[18,24-28]$. When fruit firmness decreased to about $20 \%$ of their harvest value (phase 3), fruit was considered to be in the eating ripe stage for consumers. At this stage, fruit started to produce autocatalytic ethylene, and about one week after, fruit became over-ripe and senescence (phase 4). Richardson et al. suggested that the color change of 'Hort $16 \mathrm{~A}^{\prime}$ finished at stage 85 , when the outer pericarp turned yellow with a $100^{\circ}$ hue angle [29]. But in fact, the final hue value of 'Hort $16 \mathrm{~A}^{\prime}$ ' is $\sim 97^{\circ}$ in fully ripened fruit [30], indicating the flesh yellow color change may still occur at the phase 3 stage, and it is also an important eating quality character for consumers. However, the changes in carotenoids and chlorophylls and the transcript of related genes during this stage are not fully clear.

In our previous study, we found the color indexes $\mathrm{a}^{*}$ and $\mathrm{b}^{*}$ of 'Qihong' (yellow outer pericarp and red inner pericarp) were significantly changed during their eating ripe window with firmness $\approx 20 \mathrm{~N}$ to $8 \mathrm{~N}$ [31]. It was noteworthy that, similar to the loss of firmness, the color changes were obviously affected by 1-MCP treatment [31], which greatly delayed and reduced the production of autocatalytic ethylene and resulted in the stronger yellow color and lower hue angle (Figure 1A). 

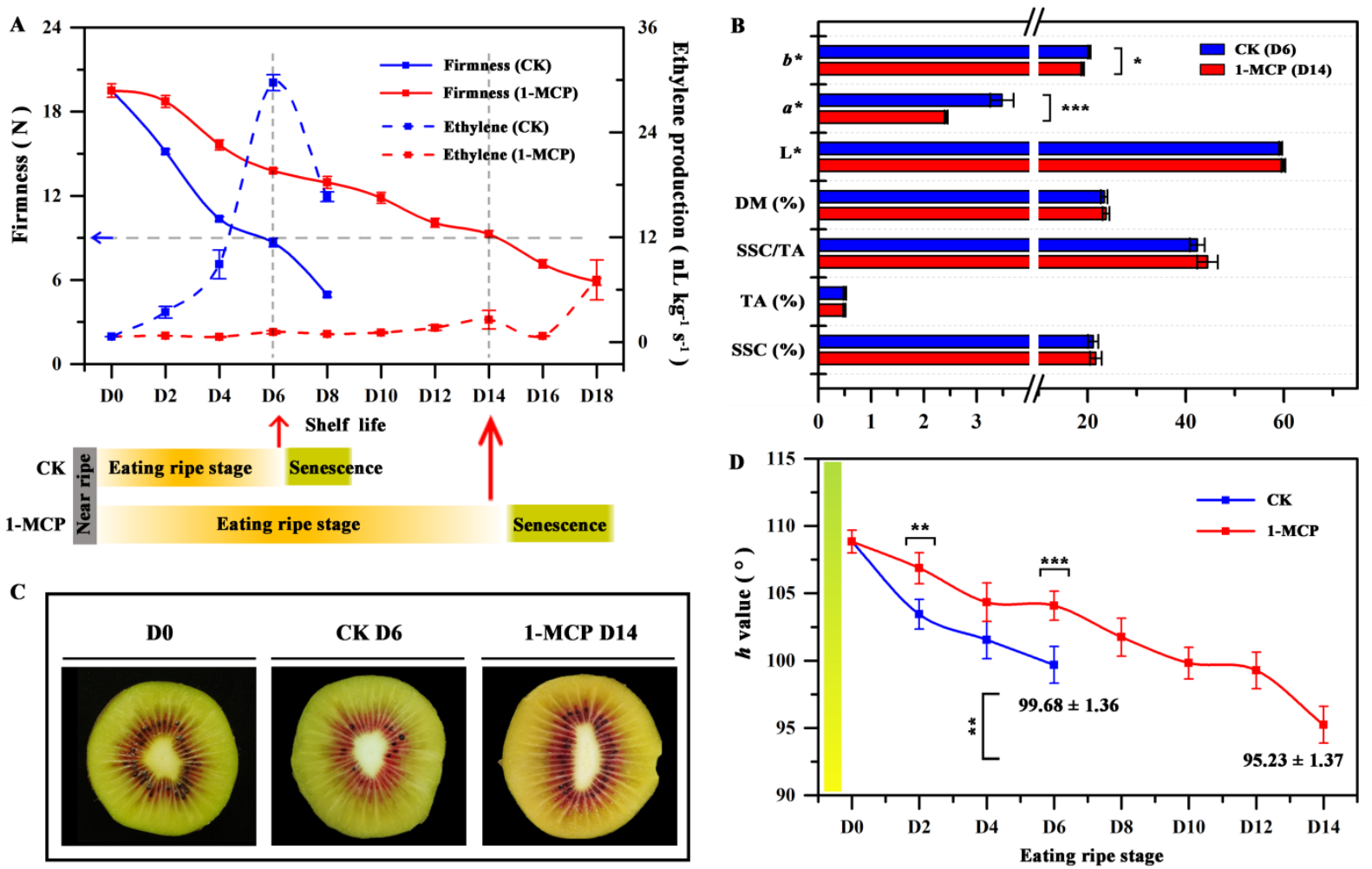

Figure 1. The fruit physiology indicators and flesh color after 1-MCP treatment. (A) fruit firmness and ethylene production; (B) SSC, TA, DM, and color of kiwifruit after 1-MCP treatment; (C) the phenotype of control fruit at D6 and 1-MCP treated fruit at D14; (D) h value during the eating ripe stage. Data are mean $\pm \mathrm{SE}(n=3)$. Values with different letters represent significant differences in the same group (1-MCP group or control group) during ripening $(p<0.05)$. Asterisk represents a significant difference between the control (CK) and 1-MCP treated fruit $\left({ }^{*} p<0.05,{ }^{* *} p<0.01\right.$ and $\left.{ }^{* * *} p<0.001\right)$.

Therefore, this study investigates the effect of 1-MCP on the flesh yellow color change in 'Qihong' during the eating-ripe stage. This includes the crucial changes in the concentrations of chlorophylls and carotenoids and the transcript profiles of genes related to pigment metabolism and ethylene response factors (ERFs). The final aim of our study was to reveal the correlation between ethylene and yellow color changes in 'Qihong' fruit and to provide a theoretical basis for improving their eating quality.

\section{Materials and Methods}

\subsection{Fruit Materials and Treatment}

Actinidia chinensis cv. 'Qihong' fruit sampled from a commercial orchard in Shannxi Province, China, in 2019 was used in this study. The harvested fruit (firmness $100.74 \mathrm{~N}$, SSC $13.9 \%$, DM $19.8 \%)$ was stored at room temperature $\left(23 \pm 1{ }^{\circ} \mathrm{C}\right)$ until they reached near eating firmness ( $20 \mathrm{~N}, 60$ fruits were used to determine the eating firmness), uniform fruit without visible wound signals were selected for further treatment. About 600 fruit were divided into control (CK) and 1-MCP groups. The control group without any treatment was placed directly into a $90 \mathrm{~L}$ sealed container for $12 \mathrm{~h}$ at $23^{\circ} \mathrm{C}$. The second group was treated with $0.5 \mu \mathrm{L} \mathrm{L}^{-1}$ 1-MCP (SmartFresh ${ }^{\circledR}$, AgroFresh, Spring House, Philadelphia, PA, USA) in the same size sealed container for $12 \mathrm{~h}, 23^{\circ} \mathrm{C}$. Subsequently, the two groups of kiwifruit were transferred to a storage room at $23^{\circ} \mathrm{C}$ [31]. At each sampling point, 27 fruit were collected from each group and divided into three replicates. The outer pericarp was immediately frozen in liquid nitrogen and stored at $-80^{\circ} \mathrm{C}$ pending analysis. 


\subsection{Measurement of Physiological Indices}

About $1 \mathrm{~mm}$ thick and $1 \mathrm{~cm}^{2}$ peel at the two opposite cheeks of each fruit were removed first, then the GS-15 Fruit Texture Analyzer (Strand, Cape Town, South Africa) with an $8 \mathrm{~mm}$ plunger was used to determine the fruit firmness [32]. Two juice samples from the equatorial part of each fruit were used to measure the soluble solid content (SSC) and titratable acidity (TA) with the PAL-1 (Atago, Tokyo, Japan). A slice sampled from the fruit equator was used to measure dry matter content. The transverse fruit slices $(2 \mathrm{~mm})$ were weighed to record their fresh weights (FW) and were placed at $75^{\circ} \mathrm{C}$ (DZF-6050, Shanghai, China) for $24 \mathrm{~h}$ (DW). Dry matter content was determined by: FW $/ \mathrm{DW} \times 100 \%$ [33]. Flesh color $\left(\mathrm{L}^{*}, \mathrm{a}^{*}\right.$ and $\left.\mathrm{b}^{*}\right)$ was measured using a CR-400 chromameter (Konica Minolta, Tokyo, Japan) [34]. Three replicates were carried out for these physiological indices.

\subsection{Carotenoid and Chlorophyll Measurements}

The chlorophylls and carotenoids were extracted from the kiwifruit according to previous methods $[3,4]$. The extracts were quantified using a high performance liquid chromatography (HPLC) system (1260 Infinity II, Agilent Technologies, Palo Alto, CA, USA) equipped with a DAD detector and a C-18 column $(250 \mathrm{~nm} \times 4.6 \mathrm{~mm}, 5.0 \mu \mathrm{m}$, GL Sciences Inc., Tokyo, Japan). The injection volume was $20 \mu \mathrm{L}$, the post-run time was $5 \mathrm{~min}$, and the flow rate was $0.7 \mathrm{~mL} \mathrm{~min}^{-1}$ at $40{ }^{\circ} \mathrm{C}$. The solvent consisted of $90 \%(\mathrm{v} / \mathrm{v})$ acetonitrile/water (A) and ethyl acetate (B). The gradient profile was $100 \%$ A (0 min), $20 \%$ A (14 min), 20\% A (20 min), and 100\% A (30 min). Chlorophyll $a$ was simultaneously monitored at $430 \mathrm{~nm}$, while lutein, $\beta$-carotene, and chlorophyll $b$ were monitored at $450 \mathrm{~nm}$.

\subsection{Gene Identification and Quantitative Polymerase Chain Reaction (qPCR) Analysis}

All gene sequences to be tested were obtained from the kiwifruit genome database as a reference $[35,36]$. The transcriptome data (PRJNA277383) was used to analyze the responses of the AcERFs to ethylene treatment and the results are shown as a heatmap. Total RNA was extracted using the Plant RNA Kit (Omega Bio-tek, Norcross, GA, USA). Then, approximately $1 \mu \mathrm{g}$ of total RNA was used for CDNA synthesis with the Prime-Script RT reagent kit (TaKaRa, Dalian, China). Quantitative real-time PCR $(20 \mu \mathrm{L})$ was monitored on the LightCycler 96 system (Roche, Basel, Switzerland) with the SYBR Premix ExTaq II Kit (TaKaRa). The amplification program was $98{ }^{\circ} \mathrm{C}$ for $30 \mathrm{~s}$ for one cycle, $95{ }^{\circ} \mathrm{C}$ for $5 \mathrm{~s}$ for 40 cycles, and $57^{\circ} \mathrm{C}$ for $30 \mathrm{~s}$. Gene expression levels were normalized with the $2^{-\Delta \Delta C T}$ method [37] using the AcActin and AcPP2A genes as internal standards. All analyses were repeated three times using biological replicates. The specific primers are listed in Table S1.

\subsection{Correlation Analysis and Network Visualization}

A correlation analysis was performed between the contents of $\beta$-carotene, chlorophyll $b$, and chlorophyll $a$, and the expression of all tested genes was carried out using OmicShare tools (http://www.omicshare.com/tools). Results were visualized as a network using Cytoscape (v3.7.1).

\subsection{Promoter Analysis}

Using the kiwifruit genome database as a reference [34,35], the promoter sequences of AcPAO2, AcSGR1, AcLCY- $\beta$, and AcCCD1 were isolated. Newplace was used to analyze potential ERF binding motifs [38].

\subsection{Dual-Luciferase Assays}

According to previous reports $[39,40]$, the promoter sequences were cloned into the pGreenII 0800-LUC vector forming the reporters, the full CDS were cloned into the pGreenII 62-SK and used as the effectors (Table S1, Figure S3). The A. tumefaciens strain GV3101pSoup were used to introduce the fused constructs. The cultures with $\mathrm{OD}_{600}$ of 0.8 were infiltrated with buffer (10 mM MgCl $2,10 \mathrm{mM} \mathrm{MES,} 200 \mathrm{mM}$ acetosyringone and $\mathrm{pH} 5.8)$. The different Agrobacterium mixtures were injected into the N. benthamiana leaves of 6- 
week-old plants. Then, tested tobaccos were classed into two groups-control (without any treatment) and 1-MCP treatment $\left(0.1 \mu \mathrm{L} \mathrm{L}^{-1}, 2 \mathrm{~h}, 23^{\circ} \mathrm{C}\right)$. After $48 \mathrm{~h}$, according to the manufacturer's instructions, the Dual-Luciferase Reporter Assay System (Promega, Madison, WI, USA) was used to detected the luciferase activity.

\subsection{Statistical Analysis}

The results were analyzed by one-way analysis of variance in SPSS 22.0 software (SPSS Inc., Chicago, IL, USA) to compare significant differences among treatments, using Duncan's multiple range test $(p<0.05)$ and Student's $t$-test $\left({ }^{*} p<0.05,{ }^{* *} p<0.01\right.$ and $\left.{ }_{* * *} p<0.001\right)$. All results are presented as mean \pm standard error.

\section{Results and Discussion}

\subsection{The Fruit Physiology Indicators and Flesh Color after 1-MCP Treatment}

The firmness of climacteric fruit is influenced by the concentrations and exposure duration to exogenous and endogenous ethylene [7]. Based on our published report [31], profiles of firmness and ethylene production were further compared between 1-MCP treated and untreated groups (see Figure 1A). 1-MCP significantly delayed and reduced the peaks of the ethylene production compared with the control fruit during storage at $23 \pm 1{ }^{\circ} \mathrm{C}$ and $90-95 \%$ RH. The firmness of control fruit declined until day 8 (D8), reaching $8.65 \pm 0.30 \mathrm{~N}$ at D6, which is the optimum period for eating (best flavor, taste, and texture) [29]. As expected, the 1-MCP treatment reduced the softening rate, and firmness declined to the key value at D14 with firmness $9.27 \pm 0.23 \mathrm{~N}$, resulting in a longer shelf life, which was similar to a previous study [25]. The combined ethylene production and firmness change meant that stage D6 and D14, respectively, identified the final stage of the eating ripe window in control and 1-MCP treated fruit (Figure 1A). No differences $(p<0.05)$ in SSC, TA, SSC/TA, or DM and L*, were found between the control (D6) and 1-MCP treated fruit (D14). However, the flesh of the 1-MCP treated fruit at D14 was more yellow in color (lower $\mathrm{a}^{*}, \mathrm{~b}^{*}$ value and $h$ value) than that of the control fruit at D6 (Figure 1B-D), indicating that the 1-MCP treatment led to higher exterior quality of 'Qihong' fruit.

\subsection{The Fruit Carotenoid Contents in 1-MCP Treated Fruit and Control Fruit}

Carotenoid, including lutein and $\beta$-carotene, are the pigments responsible for flesh coloration in yellow fleshed kiwifruit, and $\beta$-carotene is mainly responsible for the goldyellow color of kiwifruit [3,4].

Among the quantified carotenoid of the two types, the concentration of lutein decreased in both the control and 1-MCP treated groups before D6, then increased in the 1 -MCP treatment groups (Figure 2A). $\beta$-carotene decreased gradually in the control fruit during eating ripe window; while in 1-MCP treated fruit, it rapidly increased and reached a peak on D6, then was relatively smooth until D14 (Figure 2B). The $\beta$-carotene content in the 1-MCP treated fruit $\left(7.24 \pm 0.10 \mathrm{mg} \mathrm{kg}^{-1} \mathrm{FW}\right)$ was higher during the final stage than that in the control (only $4.76 \pm 0.12 \mathrm{mg} \mathrm{kg}^{-1} \mathrm{FW}$ ). Thus, the $0.5 \mu \mathrm{L} \mathrm{L}^{-1} 1$-MCP treatment may have delayed kiwifruit senescence and led to normal $\beta$-carotene biosynthesis. Our findings differ from those of previous reports $[17,20]$, who suggested that 1-MCP treatment delays the accumulation of carotenoid due to the time difference in the 1-MCP application. Both studies applied 1-MCP before fruit ripening at a time when the fruit had not finished post-ripening metabolic processes, while our study applied 1-MCP near the eating period (initiation of phase 3) when the fruit had basically finished post-ripening (phase 1 and 2), such as starch degradation, rapid accumulation of SSC, and chlorophyll degradation. 
$\mathbf{A}$
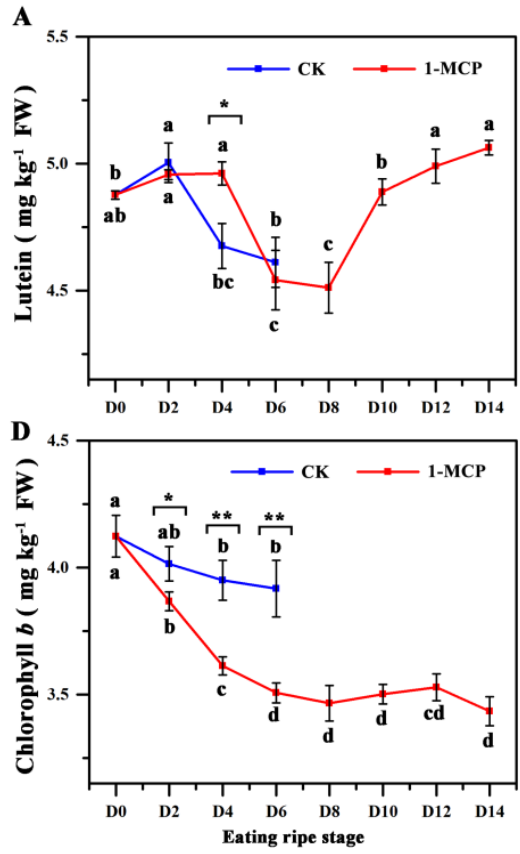

B
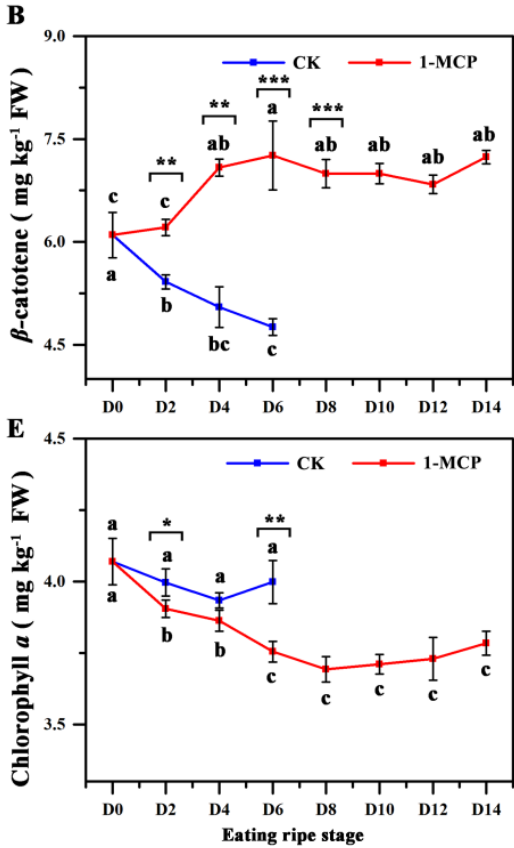
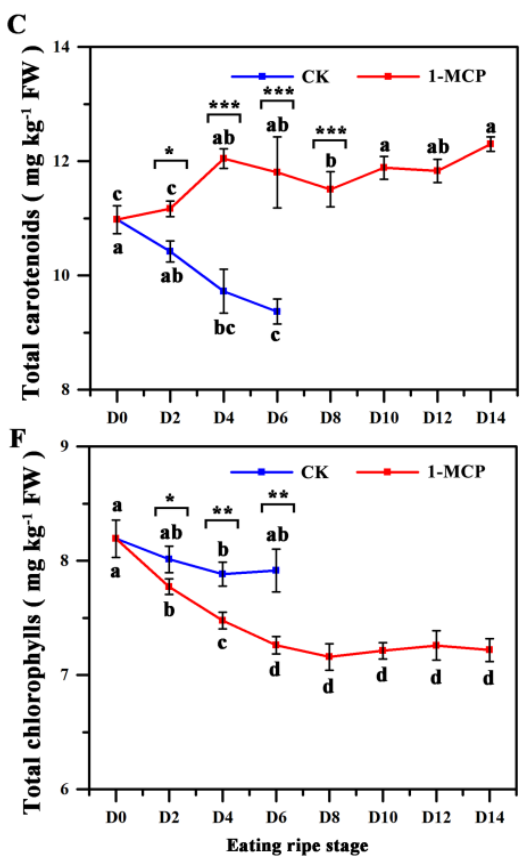

Figure 2. The contents of carotenoid and chlorophyll in treated fruit as measured by HPLC. $\beta$-Carotene (A), lutein (B), total carotenoids $(\mathbf{C})$, chlorophylls $b$ and $a(\mathbf{D}, \mathbf{E})$, and total chlorophylls $(\mathbf{F})$. Data are mean $\pm \mathrm{SE}(n=3)$. Different letters represent significant differences in the same group during ripening $(p<0.05)$. Asterisk represents a significant difference between the control (CK) and 1-MCP treated fruit $\left.{ }^{*} p<0.05,{ }^{* *} p<0.01,{ }^{* * *} p<0.001\right)$.

\subsection{The Fruit Chlorophyll Contents in 1-MCP Treated and Control Fruit}

Chlorophyll degradation is an important trait that accompanies fruit ripening in most species [6]. Exogenous ethylene accelerates the degradation of chlorophylls in mature green citrus and avocado fruit [9-11]. Exogenous 1-MCP applied to citrus, banana, apple, and pear inhibits fruit softening and delays degradation of chlorophylls during fruit ripening $[6,14,41,42]$. Interestingly in this study, as shown in Figure 2D-F, the 1-MCP treatment sped up the decrease in chlorophyll $b$, chlorophyll $a$, and chlorophyll $a+b$ content, while there was a small difference in chlorophyll contents through all of the sampled days in untreated fruit. The contents of chlorophyll $b, a$, and $a+b$, in treated fruit during the best eating period (the final stages) were $3.42 \pm 0.06,3.78 \pm 0.01$, and $7.20 \pm 0.08 \mathrm{mg} \mathrm{kg}^{-1} \mathrm{FW}$, respectively, which was $12.35,5.36$, and $7.67 \%$ lower than that in untreated fruit. These findings seem inconsistent with previous reports $[14,25,41]$.

To better explain this conflict, the reports of $\mathrm{Xu}$ et al. [25] and $\mathrm{Lv}$ et al. [14] were further investigated. Xu et al. suggested that, in green kiwifruit 'Hayward', 1-MCP treatment inhibited the process of chlorophyll degradation [25]. It was noteworthy that the chlorophyll content in untreated fruit was approximately $6.9 \mathrm{~g} \mathrm{~kg}^{-1}$ (Figure S1), which was obviously higher than that in 1-MCP treated fruit, which was about $4.5 \mathrm{~g} \mathrm{~kg}^{-1}$ at the best eating ripe stage (firmness $\sim 9 \mathrm{~N}$ ) [25]. The same result has also been found in apple fruit; it exhibited lower chlorophyll content and hue angle $\left(\mathrm{H}^{\circ}\right)$ at 49 days (ethylene peak) compared to untreated fruit at 28 days (Figure S2), though 1-MCP delayed the degradation of chlorophyll during ripening [14].

\subsection{Expression of Genes Involved in Carotenoid Biosynthesis and Degradation}

The carotenoid metabolic pathway has been studied in many fruit species [17], including kiwifruit, as shown in Figure 3A [2,35]. The expression of carotenoid metabolic pathway genes was investigated in the untreated and treated groups. AcZDS, AcCHYs, and AcNCEDs expression was not detected in any of the samples. The expression levels of AcPSY1, AcCRTISO, AcPDS, AcLCY- $\varepsilon$, and AcLCY- $\beta$, which are in the carotenoid biosyn- 
thetic pathway, were lower in control fruit than those in 1-MCP treated fruit, and gradually increased at the early stage but then decreased. The expression profiles of AcZEP1 in the 1-MCP-treated fruit increased from D2 to D6 and decreased on D8 compared with the controls. AcCCD1 is an important gene responsible for $\beta$-carotene degradation [3]. It increased in control fruit during storage, and maximum expression was detected on D6. This level was always higher than that in 1-MCP treated fruit. This finding indicated that the 1-MCP treatment inhibited the expression of AcCCD1.
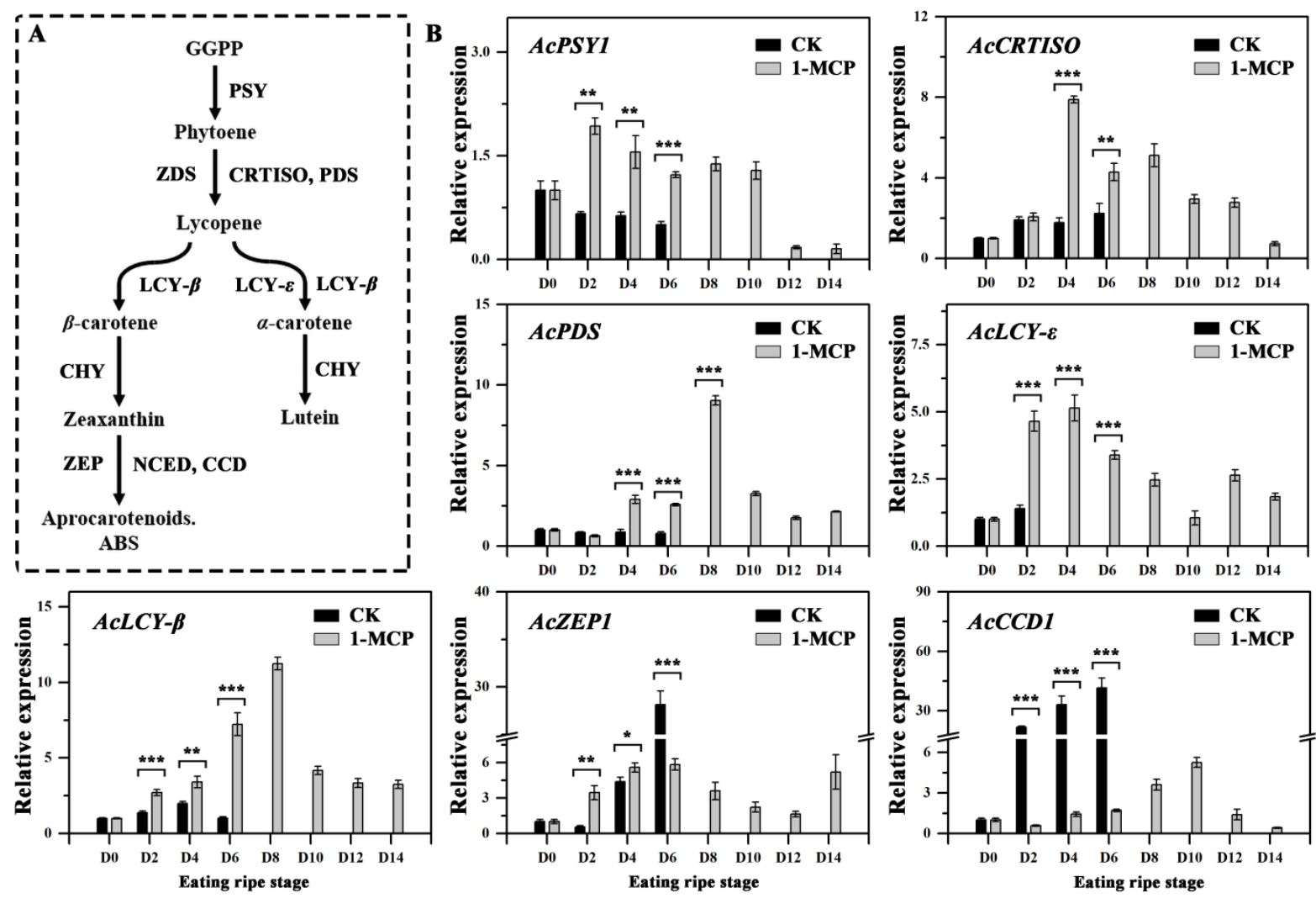

Figure 3. Expression profiles of genes involved in the carotenoid pathway in the flesh of kiwifruit. (A) Carotenoid biosynthetic and degradation pathways in kiwifruit. (B) Effect of 1-MCP on the expression profiles of carotenoid pathway related genes in the flesh during storage. The D0 stage was used as the reference ( $=1$ relative expression) for each gene. Error bars show SE of the mean. Data were analyzed with Student's $t$-test $\left.{ }^{*} p<0.05,{ }^{* *} p<0.01,{ }^{* * *} p<0.001\right)$.

\subsection{Expression of Genes Involved in Chlorophyll Degradation}

The nine genes related to chlorophyll degradation were selected (Table S1) and investigated during the post-treatment period (Figure 4). AcSGR2, AcPAO1, AcPPH2, and $A c R C C R$ were not expressed in treated or untreated fruit. It has been shown that ASGR1 and AcPAO2 are the key genes responsible for chlorophyll degradation in kiwifruit $[2,3]$. In this study, the expression of both genes increased gradually and reached a peak on D2 but then decreased sharply in control fruit; while in 1-MCP treated fruit, the expression of them was higher than that in control fruit during storage except at the D2 stage. The expression levels of $A c C B R, A c C L H$, and $A c P P H 1$ changed similarly between the control and 1-MCP treated fruit during storage. Overall, our findings suggest that the effect of $1-\mathrm{MCP}$ is to delay the increase in the expression of chlorophyll degradation genes within a short time, but it up-regulated their expression during later stages of storage. 

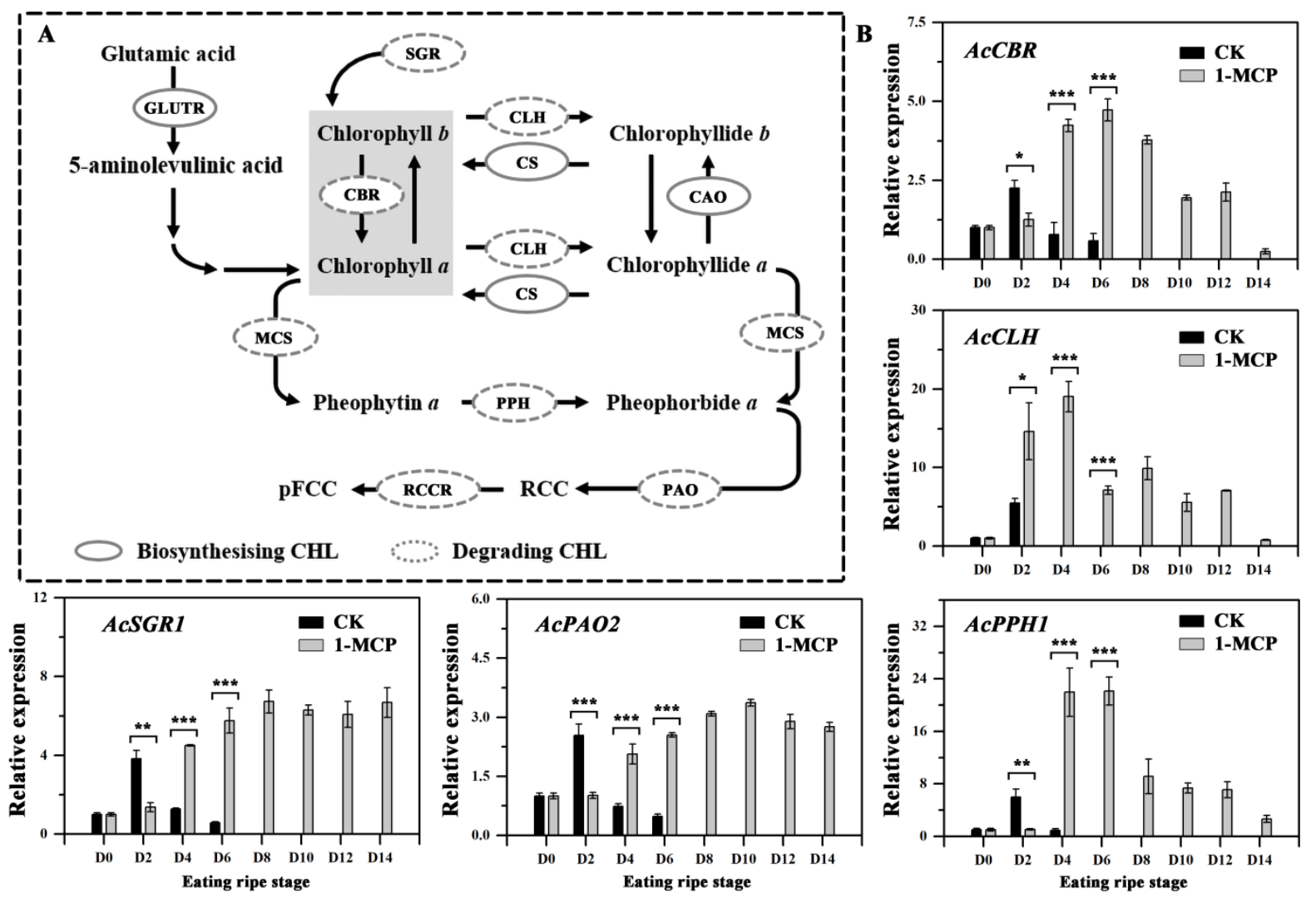

Figure 4. Expression profiles of genes involved in chlorophyll degradation in the flesh of kiwifruit. (A) Chlorophyll degradation pathway in kiwifruit. (B) Effect of 1-MCP on the expression profiles of chlorophyll degradation-related genes in the flesh during storage. The D0 stage was used as a reference (=1 relative expression) for each gene. Error bars show SE of the mean. Data were analyzed with Student's $t$-test $\left({ }^{*} p<0.05,{ }^{* *} p<0.01,{ }^{* * *} p<0.001\right)$.

\subsection{Expression of Ethylene Related Genes in Kiwifruit during Storage}

Our previous study showed that use of 1-MCP delayed the peaks of the ethylene production [31] (Figure 1A), thus it was supposed that ethylene may play an important role in the difference formation of 'Qihong' flesh color. ACO and ACS are the main ethylene producing enzymes in various fruit, such as tomato [43,44], apple [45], pear [46], and melon [47]. In kiwifruit, $A d A C O 1$ and $A d A C S 1$ have been functionally verified to be responsible for ethylene biosynthesis during fruit ripening [23,27]. As shown in Figure 5, AcACO1 and AcACS1 expression levels were similar during storage. Both genes increased from D0 and reached a peak on D4 then decreased in control fruit. The expression of these two genes in 1-MCP treated fruit was significantly lower than that in control fruit from D0 to D6. Expression then increased after this stage and reached a peak on D12. These findings agree with Wu et al. [27], who suggested that 1-MCP treatment delays AdACO1 and AdACS1 expression. 

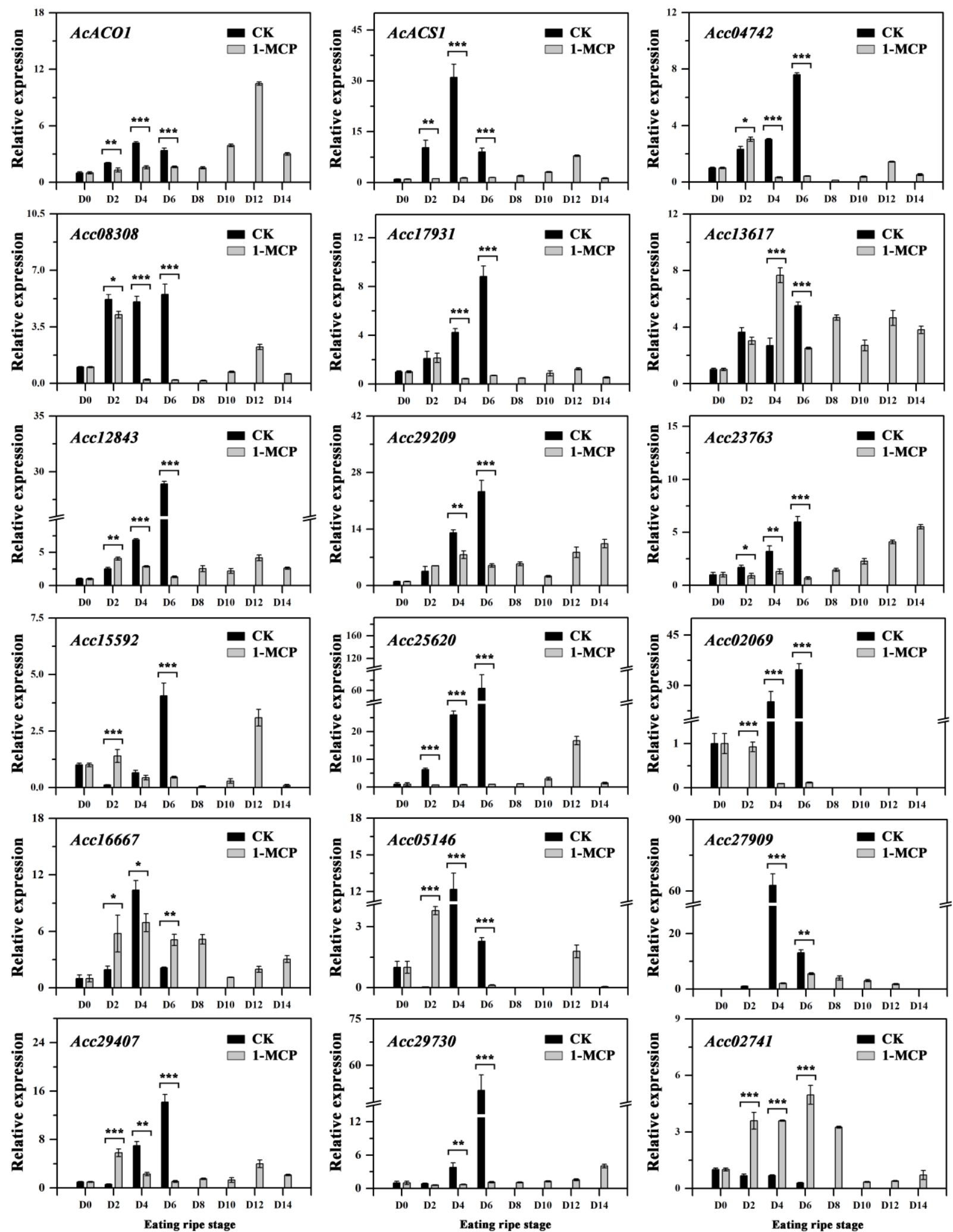

Figure 5. Expression of the ACO and ACS genes and ethylene-induced ERFs in the flesh of kiwifruit. Error bars show SE of the mean. Data were analyzed with Student's $t$-test ${ }^{*} p<0.05,{ }^{* *} p<0.01$, $\left.{ }^{* * *} p<0.001\right)$. 
It is well-known that the AP2/ERF transcription factors (TFs) play an important role in the response to 1-MCP treatment [6]. In this study, 153 individual AcAP2/ERF TFs were found in the Red 5 genome. Among them, 18 ERFs, which were up-regulated by the ethylene treatment during storage (Figure S1), were investigated further by qPCR (Figure 5). Acc22453 and Acc00583 expression was not detected in treated or untreated fruit. Acc04742, Acc08308, and Acc17931 were expressed at higher levels from D2 to D6 in control fruit than in 1-MCP treated fruit. Acc12843 and Acc29209 expression increased in control fruit during storage, and higher transcript levels were detected during D4-D6 than those in treated fruit. Notably, three genes (Acc23763, Acc25620, and Acc29730) increased continuously and reached peaks on D6 in the control fruit, while the transcript levels and the highest peaks (both abundance and time) of these genes were inhibited and delayed by the 1-MCP treatment. Acc02741 was highly expressed in 1-MCP treated fruit from D2 to D8, and the level was significantly higher than that in control fruit. In contrast, the expression of other genes, including Acc13617, Acc15592, Acc02069, Acc16667, Acc05146, Acc27909, and Acc29407 was complex and no significant pattern was found between the control and 1-MCP treated fruit.

\subsection{Correlation Analysis of Pigment Contents and Expression of Related Genes}

The correlations between the contents of $\beta$-carotene, chlorophyll $b$, and chlorophyll $a$ and the expression of all tested genes were assessed and visualized using Cytoscape (v3.7.1). As shown in Figure 6A, $\beta$-carotene content was positively correlated with the $A c L C Y-\beta$ transcript changes, but was negatively correlated with the AcCCD1 transcript. These results are consistent with previous studies suggesting that $A c L C Y-\beta$ and $A c C C D 1$ are responsible for $\beta$-carotene biosynthesis and degradation in kiwifruit, respectively $[2,3]$. Similar to the findings of these two reports, negative correlations were detected between chlorophyll contents and the AcPAO2 and AcSGR1 transcript levels. Furthermore, Acc25620, $A c c 29730$, and Acc23763 were negatively correlated with AcLCY- $\beta, A c P A O 2$, and AcSGR1, but positively correlated with $A c C C D 1$. A partial least-squares discriminant analysis (PLSDA) showed that pigment contents and the expression of several genes in the samples were classified into the control and 1-MCP treatment groups (Figure 6B).

3.8. The Activation of AcSGR1, AcPAO2, AcLCY- $\beta$ and AcCCD1 Promoters by Acc25620, Acc29730 and Acc23763 after 1-MCP Treatment

The ERF TFs have been reported to play important roles (either positive or negative) in plant growth and stress response [48,49]. In this study, all three ERFs contained the ERF motif, and an EAR motif also found in the C-terminal region of Acc23763 (Figure S2), indicating it may act as a repressor [48]. Moreover, at least three ERF binding motifs (WBOXNTERF3 or ERELEE4) [6] were found in the AcPAO2, AcSGR1, AcLCY- $\beta$, and $A c C C D 1$ promoters (Figure 6C). 

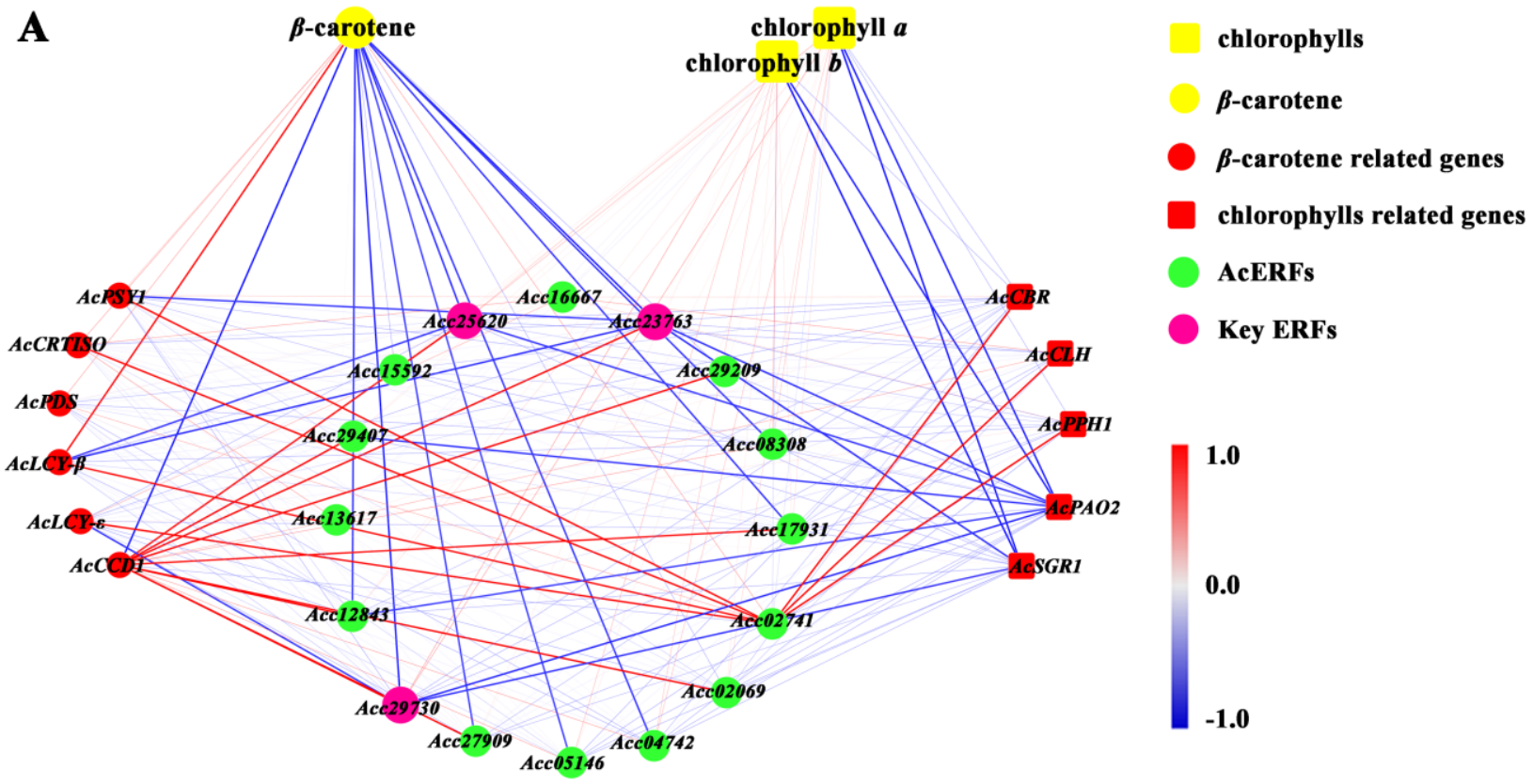

AcERFs

Key ERFs
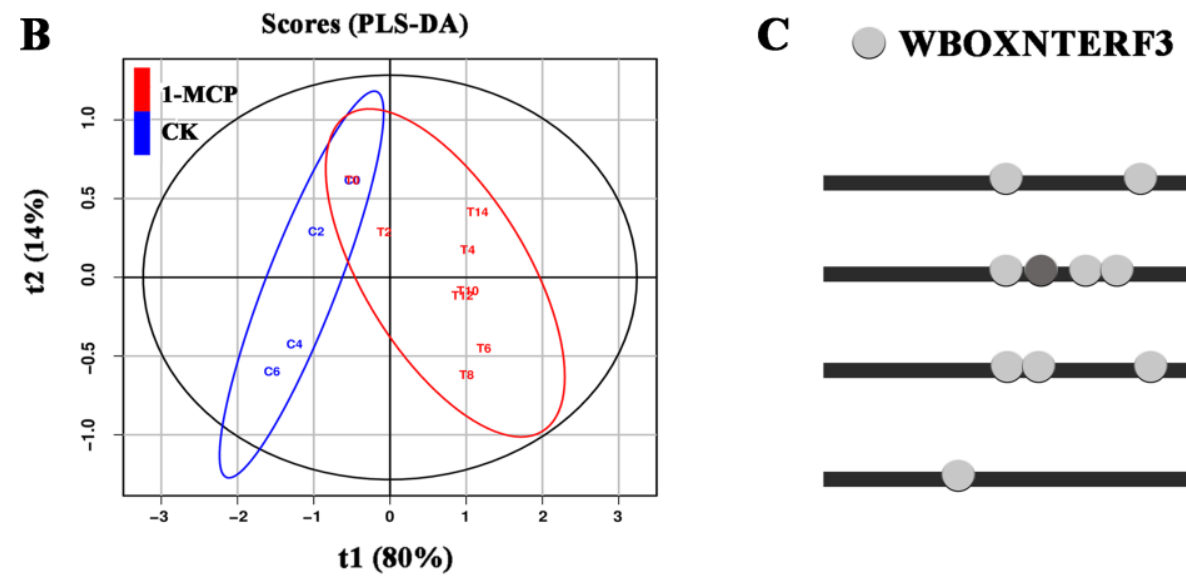

ERELEE4

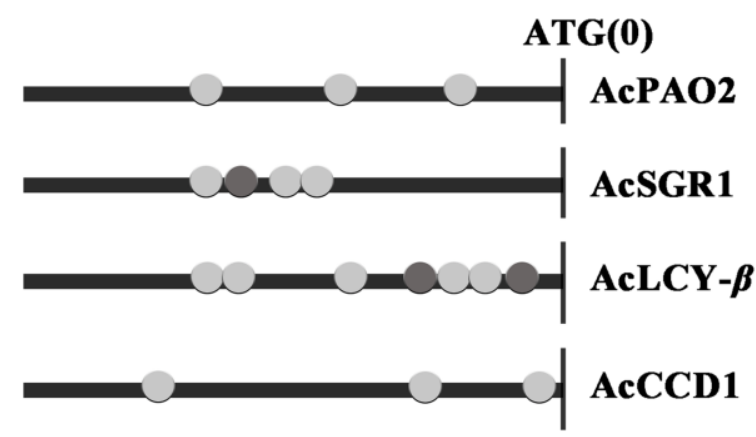

Figure 6. Correlation network and promoter analyses. (A) Correlation network analysis for pigment contents, pathway related genes, and the tested ERFs. Correlations are indicated by the colored bar. (B) The PLS-DA analysis for genes with significant correlations. (C) The promoter analysis of four important pathway related genes.

In citrus, CitERF13 enhances activity of CitPPH by directly binding to its promoter, therefore accelerating chlorophyll degradation [6]. In this study, as shown in Figure 7A, the promoters of AcSGR1 were not activated, in both control and 1-MCP treatment groups. Acc23763 strongly reduced the promoters of both AcPAO2 and AcLCY- $\beta$, however, this reduction was eliminated by 1-MCP treatment (Figure 7B, C). The promoter of AcLCY- $\beta$ was activated by Acc25620 in both control and 1-MCP groups. Acc29730 and Acc25620 strongly activated the AcCCD1 promoter by approximately 3.46- and 8.72-fold; while it was noteworthy that 1 -MCP treatment reduced above activation, no difference $(p<0.05)$ was found between the empty vector and Acc29730 and Acc25620 (Figure 7D). 

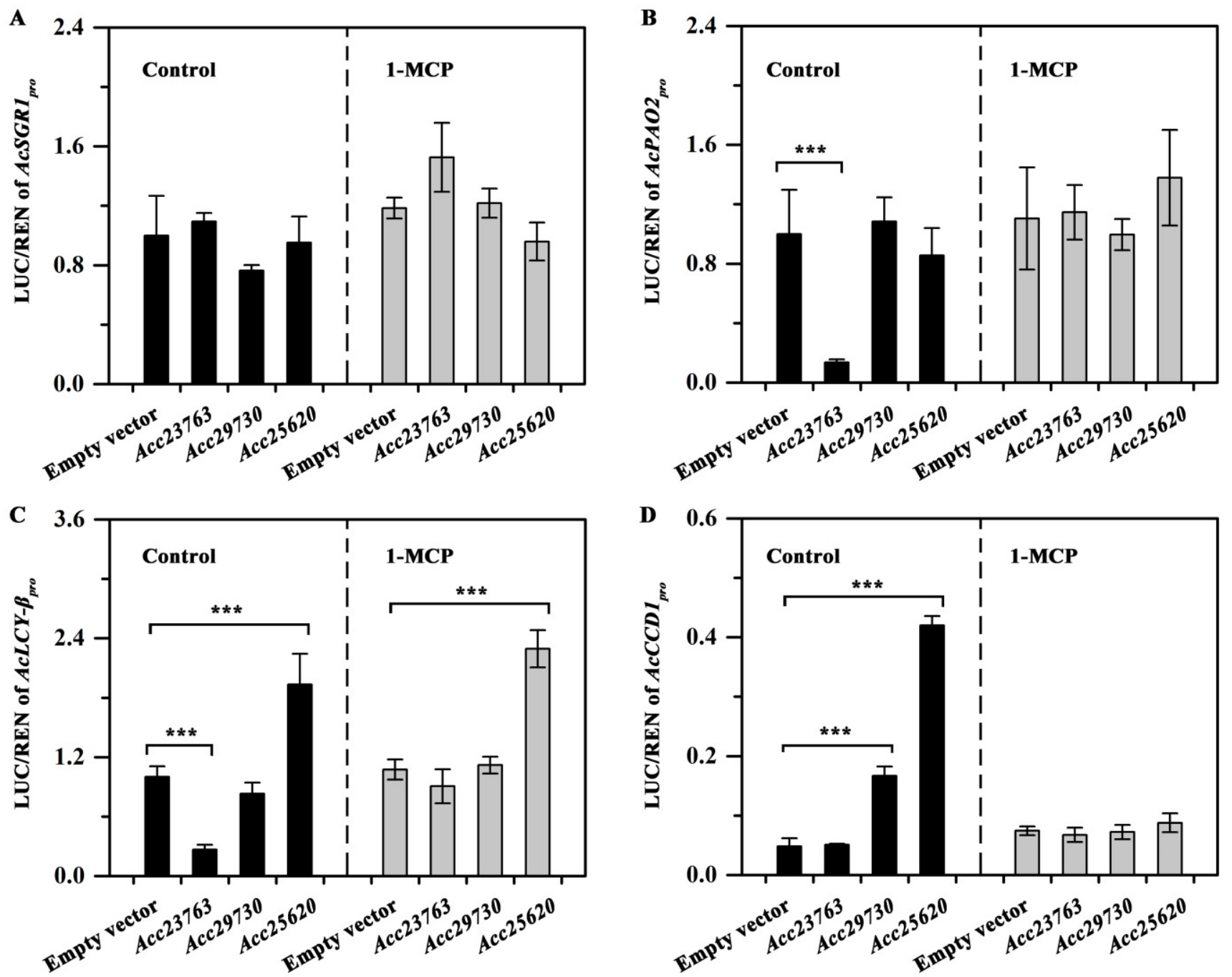

Figure 7. The activation of AcSGR1 (A), AcPAO2 (B), AcLCY- $\beta$ (C) and AcCCD1 (D) promoters by Acc25620, Acc29730, and Acc23763 after 1-MCP treatment. Error bars show the standard errors of the means $(n=3) . * * *<0.001$.

\section{Conclusions}

In this study, we showed that 1-MCP treatment affected yellow color formation of flesh in 'Qihong', which affected carotenoid accumulation and chlorophyll degradation in kiwifruit. This effect was correlated with the expression of key pathway genes, such as AcPAO2, AcSGR1, AcLCY- $\beta$, and AcCCD1. The expression of three ERFs, including Acc29730, Acc25620, and Acc23763 was delayed and down-regulated by the 1-MCP treatment, showing higher correlation with the expression of AcLCY- $\beta, A c S G R 1, A c P A O 2$, and AcCCD1. Dual-Luciferase assays showed that the inhibition of $A c c 23763$ on the promoters of both $A c P A O 2$ and AcLCY- $\beta$, and the reduction of the Acc29730 and Acc25620 on the AcCCD1 promoter were obviously eliminated by 1-MCP treatment. In summary, the development of the yellow flesh color in 'Qihong' appears to be regulated by 1-MCP, which modulated the expression of $A c c 25620, A c c 29730$, and Acc23763. These ERFs affected the promoter activities of carotenoid and chlorophyll related genes (AcPAO2, AcLCY- $\beta$ and AcCCD1) to regulate their transcript levels, leading to more yellow color in 'Qihong' fruit flesh with higher carotenoid content and lower chlorophylls content. However, this conclusion requires additional studies to verify. Overall, our study provides a theoretical basis for improving the eating quality of 'Qihong' fruit. 
Supplementary Materials: The following are available online at https: / www.mdpi.com/article/ 10.3390/foods10123017/s1, Figure S1: The firmness and chlorophyll content during storage in the report of Xu et al. 2019, Figure S2: The ethylene production, H value and chlorophyll content during storage in the report of Lv et al. 2020, Figure S3: Heatmap of AcERFs in kiwifruit during ripening. The genes signed by red boxes were used further studied, Figure S4: Amino acid sequence alignments of three AcERFs, Figure S5: Schematic diagrams used for the dual-luciferase assay, Table S1: The primers used in this study.

Author Contributions: Y.L. and G.L. designed and performed the experiments, and wrote the manuscript, J.C. and Y.Y. helped perform the experiments, Z.L. and F.M. conceived the project and revised the manuscript. All authors have read and agreed to the published version of the manuscript.

Funding: This study was supported by the China Postdoctoral Science Foundation (Grant No. 2020M673512), and the National Forestry and Grassland Extension Project (Grant No. K3130219012).

Data Availability Statement: The data presented in this study are available on request from the corresponding author. The data are not publicly available due to the data contains unpublished content from other articles.

Acknowledgments: The authors would like to thank Yutang Wang and Qianqian Shi for their suggestion in the manuscript design and discussion.

Conflicts of Interest: The authors declare no conflict of interest.

\section{References}

1. Liu, Y.; Qi, Y.; Chen, X.; He, H.; Liu, Z.; Zhang, Z.; Ren, Y.; Ren, X. Phenolic compounds and antioxidant activity in red- and in green-fleshed kiwifruits. Food Res. Int. 2019, 116, 291-301. [CrossRef] [PubMed]

2. Ampomah-Dwamena, C.; McGhie, T.; Wibisono, R.; Montefiori, M.; Hellens, R.P.; Allan, A.C. The kiwifruit lycopene beta-cyclase plays a significant role in carotenoid accumulation in fruit. J. Exp. Bot. 2009, 60, 3765-3779. [CrossRef] [PubMed]

3. Liu, Y.; Zhou, B.; Qi, Y.; Chen, X.; Liu, C.; Liu, Z.; Ren, X. Expression Differences of Pigment Structural Genes and Transcription Factors Explain Flesh Coloration in Three Contrasting Kiwifruit Cultivars. Front. Plant Sci. 2017, 8, 1507. [CrossRef] [PubMed]

4. Nishiyama, I.; Fukuda, T.; Oota, T. Genotypic differences in chlorophyll, lutein, and beta-carotene contents in the fruits of actinidia species. J. Agric. Food Chem. 2005, 53, 6403-6407. [CrossRef]

5. Jacob-Wilk, D.; Holland, D.; Goldschmidt, E.E.; Riov, J.; Eyal, Y. Chlorophyll breakdown by chlorophyllase: Isolation and functional expression of the Chlase1 gene from ethylene-treated Citrus fruit and its regulation during development. Plant J. 1999, 20, 653-661. [CrossRef] [PubMed]

6. Yin, X.R.; Xie, X.L.; Xia, X.J.; Yu, J.Q.; Ferguson, I.B.; Giovannoni, J.J.; Chen, K.S. Involvement of an ethylene response factor in chlorophyll degradation during citrus fruit degreening. Plant J. 2016, 86, 403-412. [CrossRef] [PubMed]

7. Zhu, X.; Ye, L.; Ding, X.; Gao, Q.; Xiao, S.; Tan, Q.; Huang, J.; Chen, W.; Li, X. Transcriptomic analysis reveals key factors in fruit ripening and rubbery texture caused by 1-MCP in papaya. BMC Plant Biol. 2019, 19, 309. [CrossRef]

8. Zhu, X.; Song, Z.; Li, Q.; Li, J.; Chen, W.; Li, X. Physiological and transcriptomic analysis reveals the roles of 1-MCP in the ripening and fruit aroma quality of banana fruit (Fenjiao). Food Res. Int. 2020, 130, 108968. [CrossRef] [PubMed]

9. Amir-Shapira, D.; Goldschmidt, E.E.; Altman, A. Chlorophyll catabolism in senescing plant tissues: In vivo breakdown intermediates suggest different degradative pathways for Citrus fruit and parsley leaves. Proc. Natl. Acad. Sci. USA 1987, 84, 1901-1905. [CrossRef]

10. Iglesias, D.J.; Tadeo, F.R.; Legaz, F.; Primo-Millo, E.; Talon, M. In vivo sucrose stimulation of colour change in citrus fruit epicarps: Interactions between nutritional and hormonal signals. Physiol Plant. 2001, 112, 244-250. [CrossRef]

11. Jeong, J.; Huber, D.J.; Sargent, S.A. Influence of 1-methylcyclopropene (1-MCP) on ripening and cell-wall matrix polysaccharides of avocado (Persea americana) fruit. Postharvest Biol. Technol. 2002, 25, 241-256. [CrossRef]

12. Gong, Y.P.; Mattheis, J.P. Effect of ethylene and 1-methylcyclopropene on chlorophyll catabolism of broccoli florets. Plant Growth Regul. 2003, 40, 33-38. [CrossRef]

13. Hershkovitz, V.; Saguy, S.I.; Pesis, E. Postharvest application of 1-MCP to improve the quality of various avocado cultivars. Postharvest Biol. Technol. 2005, 37, 252-264. [CrossRef]

14. Lv, J.; Zhang, M.; Bai, L.; Han, X.; Ge, Y.; Wang, W.; Li, J. Effects of 1-methylcyclopropene (1-MCP) on the expression of genes involved in the chlorophyll degradation pathway of apple fruit during storage. Food Chem. 2020, 308, 125707. [CrossRef] [PubMed]

15. Hoeberichts, F.A.; Van der Plas, L.H.W.; Woltering, E.J. Ethylene perception is required for the expression of tomato ripeningrelated genes and associated physiological changes even at advanced stages of ripening. Postharvest Biol. Technol. 2002, 26, 125-133. [CrossRef] 
16. Marty, I.; Bureau, S.; Sarkissian, G.; Gouble, B.; Audergon, J.M.; Albagnac, G. Ethylene regulation of carotenoid accumulation and carotenogenic gene expression in colour-contrasted apricot varieties (Prunus armeniaca). J. Exp. Bot. 2005, 56, 1877-1886. [CrossRef] [PubMed]

17. Wisutiamonkul, A.; Ampomah-Dwamena, C.; Allan, A.C.; Ketsa, S. Carotenoid accumulation in durian (Durio zibethinus) fruit is affected by ethylene via modulation of carotenoid pathway gene expression. Plant Physiol. Biochem. 2017, 115, 308-319. [CrossRef]

18. Kita, M.; Kato, M.; Ban, Y.; Honda, C.; Yaegaki, H.; Ikoma, Y.; Moriguchi, T. Carotenoid accumulation in Japanese apricot (Prunus mume Siebold \& Zucc.): Molecular analysis of carotenogenic gene expression and ethylene regulation. J. Agric. Food Chem. 2007, 55, 3414-3420. [CrossRef]

19. Barret, G.P.M.; Fabi, J.P.; De Rosso, V.V.; Cordenunsi, B.R.; Lajolo, F.M.; do Nascimento, J.R.O.; Mercadante, A.Z. Influence of ethylene on carotenoid biosynthesis during papaya postharvesting ripening. J. Food Compos. Anal. 2011, 24, 620-624. [CrossRef]

20. Fabi, J.P.; Cordenunsi, B.R.; de Mattos Barreto, G.P.; Mercadante, A.Z.; Lajolo, F.M.; Oliveira do Nascimento, J.R. Papaya fruit ripening: Response to ethylene and 1-methylcyclopropene (1-MCP). J. Agric. Food Chem. 2007, 55, 6118-6123. [CrossRef]

21. Ziliotto, F.; Begheldo, M.; Rasori, A.; Bonghi, C.; Tonutti, P. Transcriptome profiling of ripening nectarine (Prunus persica L. Batsch) fruit treated with 1-MCP. J. Exp. Bot. 2008, 59, 2781-2791. [CrossRef]

22. Pratt, H.K.; Reid, M.S. Chinese Gooseberry: Seasonal Patterns in Fruit Growth and Maturation, Ripening, Respiration and the Role of Ethylene. J. Sci. Food Agric. 1974, 25, 747-757. [CrossRef]

23. Atkinson, R.G.; Gunaseelan, K.; Wang, M.Y.; Luo, L.K.; Wang, T.C.; Norling, C.L.; Johnston, S.L.; Maddumage, R.; Schroder, R.; Schaffer, R.J. Dissecting the role of climacteric ethylene in kiwifruit (Actinidia chinensis) ripening using a 1-aminocyclopropane-1carboxylic acid oxidase knockdown line. J. Exp. Bot. 2011, 62, 3821-3835. [CrossRef] [PubMed]

24. Zhang, A.D.; Wang, W.Q.; Tong, Y.; Li, M.J.; Grierson, D.; Ferguson, I.; Chen, K.S.; Yin, X.R. Transcriptome Analysis Identifies a Zinc Finger Protein Regulating Starch Degradation in Kiwifruit. Plant Physiol. 2018, 178, 850-863. [CrossRef]

25. Xu, F.; Liu, S.; Liu, Y.; Xu, J.; Liu, T.; Dong, S. Effectiveness of lysozyme coatings and 1-MCP treatments on storage and preservation of kiwifruit. Food Chem. 2019, 288, 201-207. [CrossRef] [PubMed]

26. Wang, W.Q.; Wang, J.; Wu, Y.Y.; Li, D.W.; Allan, A.C.; Yin, X.R. Genome-wide analysis of coding and non-coding RNA reveals a conserved miR164-NAC regulatory pathway for fruit ripening. New Phytol. 2020, 225, 1618-1634. [CrossRef]

27. Wu, Y.Y.; Liu, X.F.; Fu, B.L.; Zhang, Q.Y.; Tong, Y.; Wang, J.; Wang, W.Q.; Grierson, D.; Yin, X.R. Methyl Jasmonate Enhances Ethylene Synthesis in Kiwifruit by Inducing NAC Genes That Activate ACS1. J. Agric. Food Chem. 2020, 68, 3267-3276. [CrossRef] [PubMed]

28. Zhang, A.; Zhang, Q.; Li, J.; Gong, H.; Fan, X.; Yang, Y.; Liu, X.; Yin, X. Transcriptome co-expression network analysis identifies key genes and regulators of ripening kiwifruit ester biosynthesis. BMC Plant Biol. 2020, 20, 103. [CrossRef]

29. Richardson, A.C.; Boldingh, H.L.; McAtee, P.A.; Gunaseelan, K.; Luo, Z.; Atkinson, R.G.; David, K.M.; Burdon, J.N.; Schaffer, R.J. Fruit development of the diploid kiwifruit, Actinidia chinensis 'Hort16A'. BMC Plant. Biol. 2011, 11, 182. [CrossRef] [PubMed]

30. De Silva, H.N.; Hall, A.J.; Burdon, J.; Lallu, N.; Connolly, P.; Amos, N. Modelling the Effect of Holding Temperature on Flesh De-Greening of 'Hort16A' (ZESPRI ${ }^{\mathrm{TM}}$ GOLD) Kiwifruit. Acta Hort. 2007, 753, 769-776. [CrossRef]

31. Chai, J.; Wang, Y.; Liu, Y.; Yong, K.; Liu, Z. 1-MCP extends the shelf life of ready-to-eat 'Hayward' and 'Qihong' kiwifruit stored at room temperature. Sci. Hortic. 2021, 289, 110437. [CrossRef]

32. Minas, I.S.; Tanou, G.; Karagiannis, E.; Belghazi, M.; Molassiotis, A. Coupling of Physiological and Proteomic Analysis to Understand the Ethylene- and Chilling-Induced Kiwifruit Ripening Syndrome. Front. Plant Sci. 2016, 7, 120. [CrossRef]

33. Famiani, F.; Baldicchi, A.; Farinelli, D.; Cruz-Castillo, J.G.; Marocchi, F.; Mastroleo, M.; Moscatello, S.; Proietti, S.; Battistelli, A. Yield affects qualitative kiwifruit characteristics and dry matter content may be an indicator of both quality and storability. Sci. Hortic. 2012, 146, 124-130. [CrossRef]

34. Hanbury, A.; Serra, J. Colour image analysis in 3D-polar coordinates. Lect. Notes Comput. Sci. 2003, 2781, $124-131$.

35. Huang, S.; Ding, J.; Deng, D.; Tang, W.; Sun, H.; Liu, D.; Zhang, L.; Niu, X.; Zhang, X.; Meng, M.; et al. Draft genome of the kiwifruit Actinidia chinensis. Nat. Commun. 2013, 4, 2640. [CrossRef]

36. Pilkington, S.M.; Crowhurst, R.; Hilario, E.; Nardozza, S.; Fraser, L.; Peng, Y.; Gunaseelan, K.; Simpson, R.; Tahir, J.; Deroles, S.C.; et al. A manually annotated Actinidia chinensis var. chinensis (kiwifruit) genome highlights the challenges associated with draft genomes and gene prediction in plants. BMC Genom. 2018, 19, 257. [CrossRef] [PubMed]

37. Livak, K.J.; Schmittgen, T.D. Analysis of relative gene expression data using real-time quantitative PCR and the 2(-Delta Delta C(T)) Method. Methods 2001, 25, 402-408. [CrossRef]

38. Higo, K.; Ugawa, Y.; Iwamoto, M.; Korenaga, T. Plant cis-acting regulatory DNA elements (PLACE) database: 1999. Nucleic Acids Res. 1999, 27, 297-300. [CrossRef]

39. Hellens, R.P.; Allan, A.C.; Friel, E.N.; Bolitho, K.; Grafton, K.; Templeton, M.D.; Karunairetnam, S.; Gleave, A.P.; Laing, W.A. Transient expression vectors for functional genomics, quantification of promoter activity and RNA silencing in plants. Plant Methods 2005, 1, 13. [CrossRef]

40. Jiang, Y.; Liu, C.; Yan, D.; Wen, X.; Liu, Y.; Wang, H.; Dai, J.; Zhang, Y.; Liu, Y.; Zhou, B.; et al. MdHB1 down-regulation activates anthocyanin biosynthesis in the white-fleshed apple cultivar 'Granny Smith'. J. Exp. Bot. 2017, 68, 1055-1069. [CrossRef]

41. Cheng, Y.; Dong, Y.; Yan, H.; Ge, W.; Shen, C.; Guan, J.; Liu, L.; Zhang, Y. Effects of 1-MCP on chlorophyll degradation pathwayassociated genes expression and chloroplast ultrastructure during the peel yellowing of Chinese pear fruits in storage. Food Chem. 2012, 135, 415-422. [CrossRef] [PubMed] 
42. Pongprasert, N.; Srilaong, V. A novel technique using 1-MCP microbubbles for delaying postharvest ripening of banana fruit. Postharvest Biol. Technol. 2014, 95, 42-45. [CrossRef]

43. Liu, M.; Pirrello, J.; Chervin, C.; Roustan, J.P.; Bouzayen, M. Ethylene Control of Fruit Ripening: Revisiting the Complex Network of Transcriptional Regulation. Plant Physiol. 2015, 169, 2380-2390. [CrossRef] [PubMed]

44. Houben, M.; Van de Poel, B. 1-Aminocyclopropane-1-Carboxylic Acid Oxidase (ACO): The Enzyme That Makes the Plant Hormone Ethylene. Front. Plant Sci. 2019, 10, 695. [CrossRef]

45. Dandekar, A.M.; Teo, G.; Defilippi, B.G.; Uratsu, S.L.; Passey, A.J.; Kader, A.A.; Stow, J.R.; Colgan, R.J.; James, D.J. Effect of down-regulation of ethylene biosynthesis on fruit flavor complex in apple fruit. Transgenic Res. 2004, 13, 373-384. [CrossRef]

46. Gao, M.; Matsuta, N.; Murayama, H.; Toyomasu, T.; Mitsuhashi, W.; Dandekar, A.M.; Tao, R.; Nishimura, K. Gene expression and ethylene production in transgenic pear (Pyrus communis cv. 'La France') with sense or antisense cDNA encoding ACC oxidase. Plant Sci. 2007, 173, 32-42. [CrossRef]

47. Ayub, R.; Guis, M.; BenAmor, M.; Gillot, L.; Roustan, J.P.; Latche, A.; Bouzayen, M.; Pech, J.C. Expression of ACC oxidase antisense gene inhibits ripening of cantaloupe melon fruits. Nat. Biotechnol. 1996, 14, 862-866. [CrossRef]

48. Nakano, T.; Suzuki, K.; Fujimura, T.; Shinshi, H. Genome-wide analysis of the ERF gene family in Arabidopsis and rice. Plant Physiol. 2006, 140, 411-432. [CrossRef]

49. Xu, Z.S.; Chen, M.; Li, L.C.; Ma, Y.Z. Functions of the ERF transcription factor family in plants. Botany 2008, 86, 969-977. [CrossRef] 